\title{
O USO DOS MÉTODOS DE PAULHUS \& KOHLER (1952) PARA PREENCHIMENTO DE LACUNAS EM SÉRIES HISTÓRICAS DE PRECIPITAÇÕES PLUVIOMÉTRICAS NO TERRITÓRIO DE IDENTIDADE PORTAL DO SERTÃO (TIPS). Paulo Roberto Santana Oliveira ${ }^{1}$; Rosângela Leal Santos ${ }^{2}$; \\ Bolsista PIBIC/CNPq, Graduando em Direito, Universidade Estadual de Feira de Santana, e-mail: paulogeojuri@gmail.com \\ Orientadora, Departamento de Tecnologias, Universidade Estadual de Feira de Santana, e-mail: rosangela.leal@gmail.com
}

PALAVRAS-CHAVE: Série de dados; Precipitação pluviométrica; Preenchimento de lacunas.

\section{INTRODUÇÃO}

A relevância da coleta e armazenamento, bem como o preenchimento de lacunas nas históricas pluviométricas se dá pela importância do estudo da dinâmica pluviométrica no TIPS e suas consequências para a produção agropecuária, determinação do balanço hídrico e reconhecimento de padrões de ocorrência de seca. Observa-se que no TIPS o evento meteorológico de maior importância é a precipitação pluviométrica. Desta forma, a sucessão desse fenômeno ao longo do ano faz-se de extrema relevância em diversos setores da natureza e da sociedade, a exemplo do abastecimento da produção agrícola. Portanto, faz-se necessário os estudos dessa natureza, bem como, no caso particular desta pesquisa, os meios de preenchimentos nas séries históricas de precipitação pluviométrica. Todavia, para o desenvolvimento de pesquisas demandadas pelos estudos climatológicos são necessárias séries históricas longas, como aponta Santos (2012), que a reconstrução de dados climáticos demandam séries longas. Entretanto, neste trabalho foram utilizadas séries mais curtas devido à escassez das mesmas. Para Heinemann et al. (2010), a análise de consistência e preenchimento dos dados climáticos deve ser realizada antes mesmo da sua assimilação e aplicação de métodos. Destarte, nesse processo são verificadas a existência de falhas bem como a consistência dos dados existentes, certificando-se ainda da existência de erros básicos associados aos valores fisicamente improváveis. Por exemplo, valores negativos para precipitação. No caso de Lacunas, não é suficiente apenas sistematizar e estudar os dados, é necessário processá-los e reconstruí-los para garantir consistência temporal e espacial aos dados medidos da maneira mais eficiente possível (Wissmann 2006). Utilizou-se então, estações próximas umas das outras, conforme utilizou Vicente-Serrano et al. (2010). Entretanto, os autores supracitados, ressalvam que tal procedimento pode gerar distorções nas séries reconstruídas, além das literaturas não apontarem critérios específicos para as escolhas das estações utilizadas.

\section{MATERIAL E MÉTODOS OU METODOLOGIA}

Localizado na Bahia, região nordeste do Brasil, entre as coordenadas 1 graus 40' S e 39 graus e 40' W e 12 graus e 40' sul e 38 graus e 20' W (BITTENCOURT e SANTOS, 2008). Foram utilizadas, nesse trabalho, trinta estações pluviométricas, identificadas pelo município de localização e pelo seu respectivo código, para o emprego dos métodos e cômputo de dados para preenchimento de falhas em estações vizinhas. O recorte temporal das séries históricas foi dos anos de 1964 a 1978. Situado numa zona de predominância de clima sub-úmido a seco, segundo a classificação de Thornthwaite, o TIPS agrega tanto municípios que fazem parte da zona de transição entre a zona úmida litorânea e a porção interiorana mais árida, mais conhecida como Agreste, quanto municípios já totalmente inseridos na zona semiárida, localizados mais para o interior do continente, e, consequentemente recebendo menor influencia das massas de ar mais úmidas, oriundas do Oceano Atlântico. 
O primeiro método aplicado foi o da média entre três estações (m1), método este, que demanda, para a sua utilização, que a precipitação anual de cada posto vizinho difira, no máximo, $10 \%$ da precipitação do posto com falha na série, tendo como resultado da precipitação estimada, a média aritmética dos três postos. A precipitação estimada, pelo m1, será a média aritmética dos três postos (PAULHUS \& KOHLER, 1952; SIMÕES, 2015), calculada através da equação (1):

$$
\mathrm{Px}=\frac{1}{3}+(P 1+P 2+P 3) \quad(\mathbf{1}) \text {. }
$$

Onde P1, P2 e P3 são respectivamente os postos pluviométricos adjacentes à estação em que houver lacunas nos dados da série histórica. O segundo método aplicado foi o da relação normal (m2), este que estimou a precipitação mensal através da média ponderada do registro das três estações vizinhas, em que os pesos são as razões entre as precipitações normais anuais. Para a aplicação do $\mathrm{m} 2$, a precipitação mensal $(\mathrm{P})$ do posto $\mathrm{x},(\mathrm{Px})$ é:

$$
\mathrm{Px}=\frac{1}{3}\left[\frac{\mathrm{Nx}}{N a} P a+\frac{\mathrm{Nx}}{N b} P b+\frac{\mathrm{Nx}}{N c} \mathrm{Pc}\right]
$$

$\mathrm{N}$ é a precipitação normal anual e os índices $\mathrm{a}, \mathrm{b}$ e c novamente representam os postos vizinhos ao posto $\mathrm{x}$.

\section{Comportamento dos métodos $\mathrm{m} 1$ e $\mathrm{m} 2$}

Das seis vezes em que o $\mathrm{m} 1$ e $\mathrm{m} 2$ foram, mutuamente, utilizados para a colmatação de dados de uma mesma estação, a diferença percentual entre os seus resultados mostrou-se pequena, apontando para uma relativa similaridade entre as precisões dos dois procedimentos. A figura 01 apresenta a representação gráfica da diferença percentual entre os métodos $\mathrm{m} 1 \mathrm{e}$ $\mathrm{m} 2$ :

\section{Diferença entre os resultados de M1 e M2 (\%)}

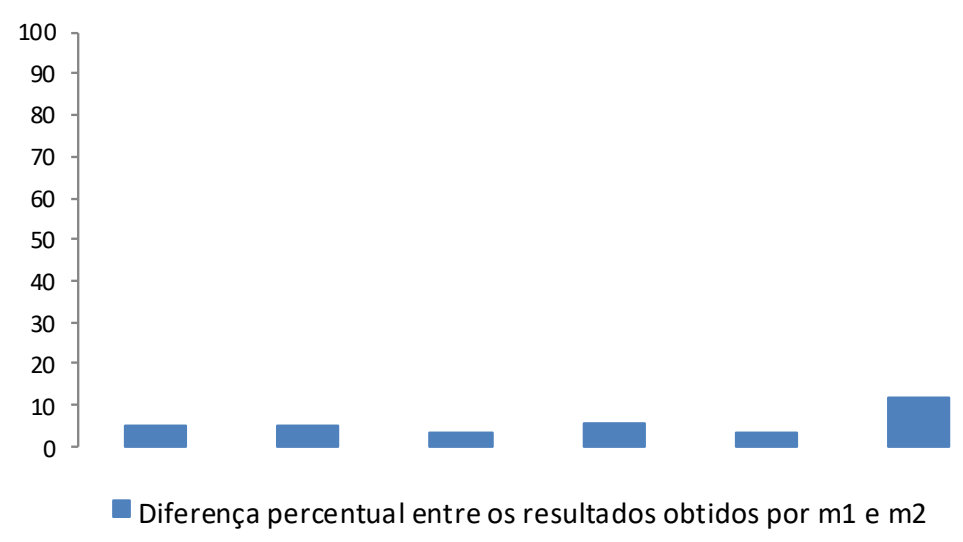

Figura 01: Gráfico de diferença percentual entre os resultados obtidos por m1 e m2.

Elaboração: Paulo Roberto S. Oliveira, 2017.

Em cinco, das seis ocasiões, a diferença entre os resultados do $\mathrm{m} 1$ e $\mathrm{m} 2$ ficaram entre aproximadamente 5 e 3,5\%, resultando numa precisão média de 95,5\%. Entretanto, em um dos casos a diferença apresentou um índice de 11,6\%, levando em conta esta última, o valor médio da precisão é decrescido para 94,3\%. Tais informações apontam para a alternativa, positiva, de utilização de um dos métodos, na impossibilidade de uso do outro, pois a diferença dos resultados mostra-se relativamente pequena. Como foi observado, neste mesmo trabalho, há maior facilidade no uso do $\mathrm{m} 2$ que do $\mathrm{m} 1$, pois este demanda diferença máxima de $10 \%$ no total anual de chuvas entre as estações utilizadas para o preenchimento de falhas nas séries históricas de precipitação pluviométrica.

No tocante à variabilidade percentual entre os resultados em relação aos dados de controle e validação, dentro de um único método, verificou-se que um deles a variabilidade foi bem maior. Tal informação, para o $\mathrm{m} 1$, é representada graficamente na figura 03 : 


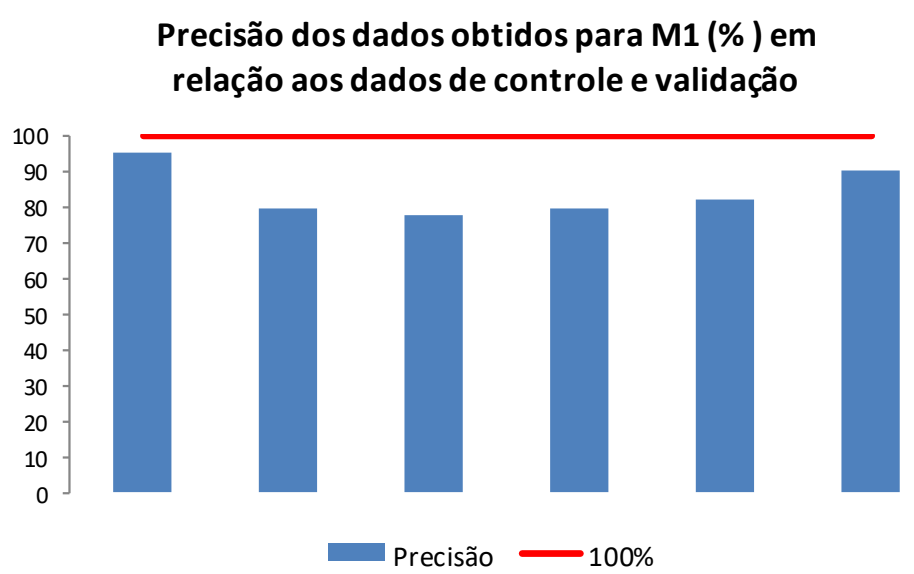

Figura 03: Gráfico de variabilidade percentual da precisão dos resultados obtidos pelo $\mathrm{m} 1$ em relação aos dados de controle e validação.

Elaboração: Paulo Roberto S. Oliveira, 2017.

A visualmente já é possível observar a pouca variabilidade percentual da precisão dos resultados obtidos pelo $\mathrm{m} 1$ em relação aos dados de controle e validação. A diferença entre o maior e o menor valor foi de $17,1 \%$. A média dos valores percentuais de precisão dos dados obtidos por m1 em, em relação aos dados de controle e validação, ficou em torno de $84 \%$. Cabe ressaltar que o $\mathrm{m} 1$ foi aplicado em apenas seis, das vinte e cinco estações que precisaram de preenchimento. Tal aspecto, não possibilitou de maneira inexorável o menor desvio entre os resultados fazendo com que a variabilidade fosse relativamente baixa, contudo, facilitou tal acontecimento.

A variabilidade percentual entre os resultados obtidos pelo $\mathrm{m} 2$, em relação aos dados de controle e validação, pode ser visualizada na figura 04 :

Precisão dos dados obtidos para M2 (\%) em ralação aos dados de controle e validação

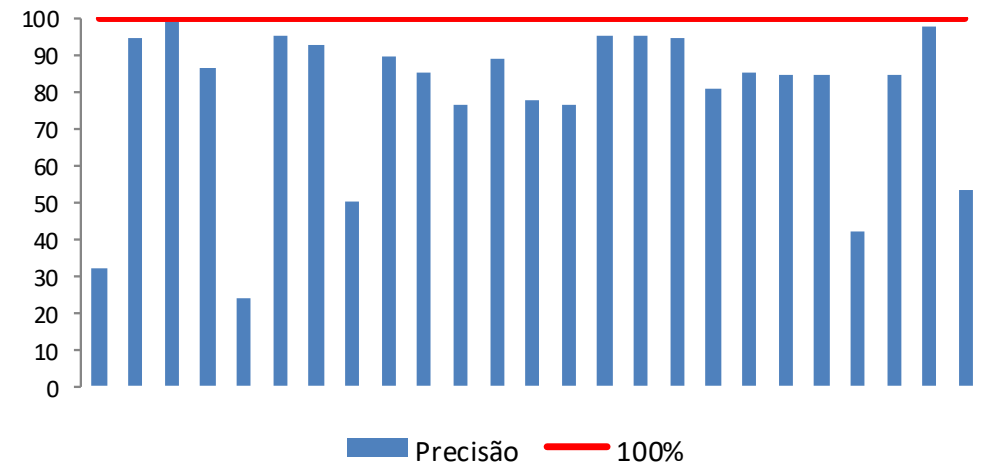

Figura 04: Gráfico de variabilidade percentual da precisão dos resultados obtidos pelo $\mathrm{m} 2$ em relação aos dados de controle e validação.

Elaboração: Paulo Roberto S. Oliveira, 2017.

Uma breve visualização no gráfico permite perceber que a variabilidade percentual da precisão dos resultados obtidos pelo $\mathrm{m} 2$ em relação aos dados de controle e validação foi relativamente grande. Isso ocorreu, não necessariamente por conta do maior número de aplicações do referido procedimento, todavia, inversamente proporcional ao pouco uso do $\mathrm{m} 1$, a utilização do $\mathrm{m} 2$ em todas as estações que demandaram preenchimentos facilitou a ocorrência duma variabilidade mais alta. A diferença entre o maior e o menor valor registrado foi de 75,2\%. A média dos valores percentuais de precisão dos dados obtidos por $\mathrm{m} 2 \mathrm{em}$, em relação aos dados de controle e validação, ficou em torno de $78 \%$, diferenciando-se, apesar da maior variabilidade, em apenas $6 \%$ da mesma variável para $\mathrm{m} 1$. 
Conjectura-se que a maior variabilidade do $\mathrm{m} 2$ em relação ao $\mathrm{m} 1$ se da por conta dos pesos para a aplicação das equações. Em ambos os casos os pesos são as razões entre as precipitações normais anuais de cada estação. Entretanto, como já explicitado na metodologia, o m1 demanda diferença máxima de $10 \%$ no total anual de chuvas entre as estações utilizadas para o preenchimento de falhas nas séries históricas de precipitação pluviométrica. Já o $\mathrm{m} 2$, utiliza os mesmos pesos, todavia, sem estabelecer uma diferenciação máxima entre o total pluviométrico anual de cada estação utilizada no respectivo procedimento favorecendo à variabilidade mais alta.

\section{CONSIDERAÇÕES FINAIS}

Os métodos e procedimentos da média entre três estações e o método da relação normal mostraram-se eficazes em suas propostas, de modo que os objetivos estabelecidos nesta pesquisa foram alcançados com relativa facilidade de aplicação, apesar da complexidade de sistematização dos dados, tendo em vista a grande quantidade dos mesmos.

Os resultados alcançados, quando comparados com os pontos de controle de coleta e amostra, apresentaram precisão satisfatória. O que apontou para um índice de qualidade eficaz e de confiabilidade. Todavia, os métodos se diferenciaram. $\mathrm{O} \mathrm{m} 2$ pode ser utilizado para o preenchimento de lacunas de qualquer estação, enquanto que o m1 pode ser usado apenas nas situações em que a precipitação anual de cada posto vizinho diferiu, no máximo, $10 \%$ da precipitação do posto com falha na série. Tal requisito restringiu o uso do $\mathrm{m} 1$, entretanto, fez com que a variabilidade percentual da precisão dos seus resultados em relação aos dados de controle e validação fosse mais baixa que a variabilidade dos mesmos dados de $\mathrm{m} 2$. Isso fez também com que o grau de confiabilidade do preenchimento obtido por $\mathrm{m} 1$ fosse ligeiramente mais alto, devido à similaridade do comportamento anual de precipitação das estações computadas na sua aplicação. $\mathrm{O} \mathrm{m} 2$ perde um pouco da sua confiabilidade, em relação ao $\mathrm{m} 1$, além de aumentar à variabilidade percentual da precisão dos seus resultados, em relação aos dados de controle e validação, por conta de não estabelecer um parâmetro de diferença máxima do total pluviométrico entre as estações utilizadas para o cômputo do preenchimento das falhas, todavia, conta com a vantagem de ser utilizado para a colmatação de dados em qualquer estação, seja o m1 aplicado ou não.

\section{REFERÊNCIAS}

BITTENCOURT, Daiane Castro; SANTOS, Rosângela Leal. Características ambientais do Território de Identidade Portal do Sertão. Feira de Santana. Dezembro de 2008. Disponível em: http://www.ebah.com.br/content/ABAAAAOlIAF/diagnostico-potencialagroambiental-territorio-identidade-portal-sertao-parte-i. Acesso: 11 Novembro 2016 às 14h $56 \mathrm{~min}$.

HEINEMANN, A. B.; LOPES JR., S.; SILVA, S.C., FERNANDES, D.S. Base de dados climáticos para a região produtora de arroz de terras altas. EMBRAPA-GO, 2010.

PAULHUS, J.L.H.; KOHLER, M.A. Interpolation of missing precipitation records. Monthly Weather Review, v. 80, n. 8, 1952. p. 129-133.

SANTOS, Roziane Sobreira dos. Homogeneidade e reconstrução de séries climatológicas para localidades no estado de minas gerais. 2012. 100f. Tese (Doutorado em Meteorologia Agrícola) - Universidade Federal de Viçosa.

SIMÕES, Yagho de Souza. Análise de tendências do comportamento de chuvas no estado na Bahia. 2015. 226f. Monografia (Graduação em Engenharia Civil) - Universidade Estadual de Feira de Santana.

WISSMANN, J. A. Ferramenta Computacional para Análise de Consistência de Dados Pluviométricos. Varia Scientia, 2006, pp.99-106. 